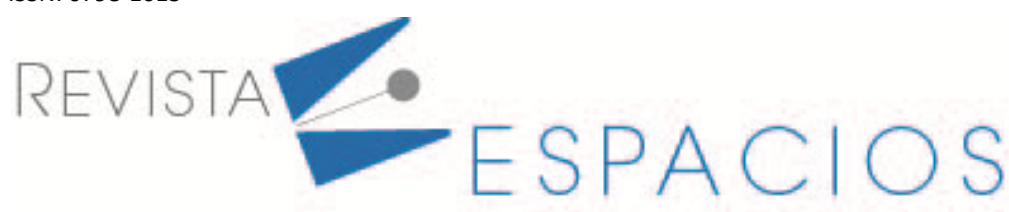

Vol. 41 (50) $2020 \cdot$ Art. 7

Recibido/Received: 07/09/2020 • Aprobado/Approved: 02/11/2020 • Publicado/Published: 30/12/2020

\title{
Análise do potencial de desenvolvimento do ecossistema empreendedor da cidade de Lorena no Brasil
}

\author{
Development potential analysis of the entrepreneurial ecosystem in the city Lorena, Brazil
}

\author{
CORRADI, Mariana G. ${ }^{1}$ \\ PEREIRA, Marco A. C. ${ }^{2}$
}

\section{Resumo}

Um ecosistema emprendedor é constituido de diferentes atores que se relacionam para sustentar a atividade empreendedora em um local. Um estudo de caso foi feito a partir de nove diferentes categorias de atores visando analisar o potencial empreendedor da cidade de Lorena, Brasil. Apurou-se que o ecossistema da cidade encontra-se em fase embrionária devido a baixa articulação e integração entre os seus principais atores, mas com bom potencial de desenvolvimento.

Palavras-chave: ecossistema empreendedor, estudo de caso, LIrena

\begin{abstract}
An entrepreneurial ecosystem is made up of different actors that relate to sustain entrepreneurial activity of a given place. A case study was conducted using nine different categories of actors in order to analyze the entrepreneurial potential of the city of Lorena, Brazil. The results demonstrate that the ecosystem within the city is still at an initial stage due to the low articulation and integration between the main entrepreneurship actors, but with good development potential.

Keywords: entrepreneurial ecosystem, case study, lorena
\end{abstract}

\section{Introdução}

O Vale do Paraíba é um acidente geográfico no Brasil que abrange uma região com parte no estado de São Paulo e outra parte no estado do Rio de Janeiro. A região destaca-se por deter uma parcela do PIB do Brasil. Lorena, uma cidade de porte médio, com uma população de 88.706 habitantes (IBGE, 2019), faz parte da região e está localizada entre as duas maiores cidades do Brasil: São Paulo a $189 \mathrm{Km}$ e Rio de Janeiro a $248 \mathrm{Km}$. Lorena conta com três universidades, sendo uma delas, um campus da Universidade de São Paulo. Estes fatores contribuem para que Lorena mostre-se como um espaço de interesse para iniciativas empreendedoras. A cidade possui um diversificado parque de indústrias de pequeno e médio porte, bem como uma forte vocação para comércio e serviços, com destaque no Ensino Superior, devido as três universidades instaladas.

Um ecossistema empreendedor é constituído por distintos stakeholders que possuem algum grau de interação entre si e com iniciativas relacionadas ao empreendedorismo. Isenberg (2011) defende que o ecossistema empreendedor, potencialmente, "substitui" ou torna-se um requisito para a implementação bem-sucedida de uma estratégia de clusters, sistemas de inovação, economia do conhecimento e políticas de competitividade em

\footnotetext{
${ }^{1}$ Graduanda. Escola de Engenharia de Lorena, Universidade de São Paulo. Email: mariana.grastiquini.corradi@usp.br

2 Professor. Escola de Engenharia de Lorena. Universidade de São Paulo. Email: marcopereira@usp.br
} 
um meio. Geralmente, estão ligados geograficamente, porém não presos a um tamanho específico ou mínimo, podendo apresentar-se num campus universitário, numa cidade ou em uma região. Também não estão necessariamente relacionados a grandes espaços ou regiões, sendo que Cambridge, Inglaterra ou Austin, Texas são exemplos de pequenas cidades com ecossistema empreendedor bem desenvolvidos (Mason; Brown, 2014).

Lorena possui potencial empreendedor e conta com uma gama de pequenos, médios e grandes empreendedores, e, dessa forma, "informalmente" parece já possuir algumas características de um ecossistema empreendedor.

O objetivo deste artigo é apresentar uma análise sobre o potencial de desenvolvimento do ecossistema empreendedor de Lorena visando seu fortalecimento e sinergia.

\section{Fundamentação teórica}

\subsection{Empreendedorismo}

A quantidade de definições para empreendedorismo encontrada na literatura difere acerca de várias dimensões de acordo com Davidsson (2003). Por exemplo, se o empreendedorismo deve ser definido em termos de organização, comportamento ou resultados; se pertence ao domínio econômico-comercial ou se também pode se encaixar em contextos sem fins lucrativos; se pertence apenas a pequenas empresas ou em quaisquer organizações e, ainda, se propósito, crescimento, risco, inovação ou sucesso são critérios necessários para descrever e qualificar empreendedorismo (Davidson, 2003).

Inerente a todas as perspectivas está o processo de criação. Assim, o empreendedorismo pode ser mais bem caracterizado como um processo de criação de risco, no qual os processos são frequentemente produtos de uma mistura de componentes de habilidade e performance (Urban, 2012), que conforme Andrade et al (2016A, 2016B), consiste em um fator essencial para transformar uma criação em uma inovação.

\subsection{Ecossistema emprendedor}

O termo "ecossistema", emprestado da biologia, descreve a combinação entre seres e ambiente e suas interrelações. Assim, analogamente, Stam e Spigel (2016) se referem ao ecossistema empreendedor como a interação de condições sistêmicas e estruturais, considerando tanto os componentes bióticos, quanto os abióticos do ecossistema empreendedor (Stam, Spigel, 2016).

O conceito de ecossistema foi introduzido na literatura de gestão e negócios primeiramente por Moore, em 1993, quando propôs que ecossistemas de negócios condensam capital, interesse do consumidor e talento gerado por uma inovação, assim como espécies vivas bem-sucedidas absorvem recursos naturais como água, luz e nutrientes (Moore, 1993).

Atualmente, existe uma grande quantidade de definições, modelos e padrões propostos para ecossistema empreendedor. Uma visão amplamente reconhecida é a de que todo empreendedor e seu respectivo negócio são parte de um (eco)sistema maior que conta com consumidores, regulamentação, investidores, outros empreendedores, espaço, agências de suporte e provedores (Neumeyer, Santos, 2017).

Um ecossistema empreendedor, de acordo com a Organização para a Cooperação e Desenvolvimento Econômico (OCDE), é holístico e interativo por natureza, no qual, conceitos como clusters, distritos industriais, sistemas locais de inovação, e regiões de aprendizagem moldam as políticas locais de desenvolvimento econômico (Carvalho, 2016). Uma outra abordagem, sugerida por Neumeyer e Santos (2016), indica que o conceito de um ecossistema empreendedor enfatiza, também, a necessidade por diversidade, tanto no âmbito individual como no organizacional. 
Percebe-se, portanto, que um ecossistema empreendedor não depende exclusivamente de um fator, mas sim das empresas (e todas as relações que elas trazem), a quantidade e qualidade das interações com as partes interessadas externas (desde empresas até investidores, passando também por organizações públicas, universidades e institutos de pesquisa) e de como as interações são organizadas (Carvalho, 2016).

\subsection{Os componentes do ecossistema empreendedor}

Ecossistemas empreendedores costumam surgir em locais que têm ativos específicos (Carvalho, 2016). Componentes comuns entre os diversos estudos e definições para o conceito são uma cultura favorável, capital (de risco), redes ativas de empreendedores, políticas públicas de desenvolvimento, investidores e a presença de universidades e serviços de suporte (Neumeyer; Santos 2016).

De forma similar, Isenberg (2011) definiu seis domínios inerentes ao sistema empreendedor: políticas públicas, capital financeiro, cultura, instituições/profissões de suporte, recursos humanos e mercados. Esses seis domínios se inter-relacionam entre si. Este modelo de Isenberg (2011) prega que um ecossistema inteiro de variáveis é necessário para garantir que o empreendedorismo se sustente a longo prazo e traga impactos sociais e econômicos positivos para a economia do meio. O modelo proposto por Arruda et al. (2014) corrobora essa visão, pontuando que não há apenas uma característica ou fator determinante para o sucesso do empreendedorismo local.

Spiegel (2017) também defendeu que um ecossistema empreendedor é composto por diferentes atributos. Estes são divididos nos âmbitos cultural, social e material e provém benefícios e recursos aos empreendedores. Já Neumeyer e Santos (2016), por sua vez, partiram de três linhas da literatura: modelos sustentáveis de negócios, teoria do networking e ecossistemas empreendedores; e chegaram a um entendimento de como empreendedores convencionais e sustentáveis se relacionam. Este modelo inclui fatores de nível organizacional e de nível individual, que impactam na conectividade da rede de negócios sustentáveis e convencionais. Assim, é possível medir como empreendedores sustentáveis se conectam e relacionam em diferentes ecossistemas.

Alguns ambientes favorecem a criação, desenvolvimento e manutenção de ecossistemas empreendedores, tais como a existência de indústrias, atrações culturais, empresas estabelecidas, pesquisa e desenvolvimento, dentre outros (VOGEL, 2013). Assim, da mesma forma que, na biologia, o sistema de organismos vivos é considerado o centro do ecossistema, no empreendedorismo, condições como rede de empreendedores, liderança, finanças, talento, conhecimento, finanças, políticas e serviços de suporte são considerados o centro do ecossistema empreendedor (Stam; Spiegel 2016).

\section{Metodologia}

Visando analisar a existência e o potencial de um ecossistema empreendedor em Lorena, um estudo de caso foi feito. Tal método consiste em uma pesquisa empírica que investiga um fenômeno contemporâneo dentro de seu contexto real (YIN, 2014). Este método permite que as questões: por quê, o que e como, sejam respondidas a partir do conhecimento da natureza e complexidade do fenômeno estudado (Mereedith 1998).

O estudo de caso realizado se baseou-se no modelo de seis passos propostos por Miguel (2007): Estrutura Conceitual-Teórica, Planejamento, Teste piloto, Coleta de dados, Análise de Dados e Relatório final.

O primeiro passo para a definição da estrutura conceitual teórica foi a realização de uma Análise Bibliométrica, que consiste em uma análise que fornece uma visão abrangente do tema de interesse, não dependente dos objetivos (Barros et al., 2017). A partir disso, um framework de pesquisa foi construído. 
Na segunda etapa, o planejamento dos casos ocorreu a partir do framework proposto. Nessa etapa, foi definido um roteiro de perguntas para ser aplicado em entrevistas na coleta de dados, que foi executado em um teste piloto, de forma a verificar a qualidade dos dados obtidos e a eficiência do questionário.

$\mathrm{Na}$ etapa de coleta de dados, o roteiro de perguntas validado no teste piloto, foi aplicado em 27 entrevistas semiestruturadas. Esse tipo de entrevista conta com uma lista de perguntas que pode variar de uma entrevista para a outra. Assim, algumas perguntas pré-elaboradas podem ser omitidas ou adicionadas dependendo do contexto específico encontrado nos tópicos de pesquisa (Saunders; Lewis; Thornhill, 2009).

A análise dos dados foi feita a partir do método de Análise de Conteúdo (Bardin, 2006) através do software Iramuteq (Ratinaud; ARCHAND, 2012). A Análise de Conteúdo é usada para interpretar dados de qualquer origem a partir de inferências, compreendendo fatos a partir de indícios e raciocínios (Bardin, 2006). Após esse tratamento, os dados passaram por validação e cruzamento por meio de Triangulação (Easgterby-ASTERBYSmithS et al, 1999)

\section{Resultados}

\subsection{O Framework da pesquisa}

\subsubsection{Análise bibliométrica}

O primeiro passo para a construção do framework de pesquisa foi a realização de uma Análise Bibliométrica feita a partir da base de dados Scopus, base ampla e que inclui revistas além das que estão presentes no Journal Citation Reports (JCR) e é muito rigorosa na indexação (LUIZ, 2017). Outra razão para a escolha da base Scopus é a sua abrangência na área de interesse, bem como a facilidade e praticidade para seu uso.

Para a pesquisa em questão, a palavra chave utilizada foi "entrepreneurial ecosystem" termo em inglês para

"ecossistema empreendedor". Foram encontrados 596 artigos e publicações entre 2010 e 2018 que constituíram o portfólio inicial da pesquisa.

Os 596 artigos foram delimitados usando os filtros, disponíveis no Scopus, "engineering" e "business, management and accounting", concentrando, assim, os 62 artigos de maior interesse da pesquisa.

A última etapa consistiu em uma triagem. Foi verificada a existência de artigos repetidos e, a partir disso, as publicações encontradas foram submetidas a uma leitura dos títulos e resumos para descartar artigos que não se encaixaram com os temas desejados. Em seguida, foi feita uma leitura para scannear as principais informações de cada artigo e, assim, separá-los de acordo com o objetivo da pesquisa.

Dessa forma, finalizou-se o portfólio com 20 publicações que envolvem e abordam temas desde o ecossistema empreendedor e empreendedorismo em geral, até estudos de casos semelhantes.

\subsubsection{O framework da pesquisa}

A partir destes 20 artigos selecionados, foram identificados dez diferentes categorias para um ecossistema empreendedor: investidores, mentores, capital humano, universidades, instituições de suporte, finanças e fundos, serviços de suporte, mercado, cultura e politicas públicas. Cada uma dessas categorias é composta por diferentes atores que são individuos (pessoas fisicas) ou organizações (pessoas juridicas).

O quadro 1 apresenta essas dez diferentes categorias que compõem um ecossistema empreendedor tendo como base os artigos do portfólio com mais relevância para o tema. 
Quadro 1

Identificação das categorias que compõem um ecossistema empreendedor

\begin{tabular}{|c|c|c|c|c|c|c|}
\hline Categoria & $\begin{array}{c}\text { Carvalho } \\
\text { (2018) }\end{array}$ & $\begin{array}{c}\text { Neumeyer; } \\
\text { Santos } \\
\text { (2018) }\end{array}$ & $\begin{array}{c}\text { Ngongoni; } \\
\text { Grobbelaar } \\
\quad(2017)\end{array}$ & $\begin{array}{c}\text { Isenberg } \\
\text { (2011) }\end{array}$ & $\begin{array}{c}\text { Cavallo; } \\
\text { Ghezzi; } \\
\text { Balocco } \\
\text { (2018) }\end{array}$ & $\begin{array}{c}\text { Nicotra; } \\
\text { Romano; } \\
\text { Giudice; } \\
\text { Schillac } \\
\text { (2017) }\end{array}$ \\
\hline Investidores & & $x$ & & $\mathrm{x}$ & $x$ & $x$ \\
\hline Mentores & & & & $x$ & & \\
\hline Capital Humano & & $\mathrm{X}$ & $x$ & $\mathrm{X}$ & $\mathrm{X}$ & $x$ \\
\hline Universidades & $\mathrm{x}$ & $\mathrm{X}$ & & $x$ & & $\mathrm{x}$ \\
\hline Instituições de suporte & & $\mathrm{X}$ & $\mathrm{x}$ & & $\mathrm{X}$ & $\mathrm{x}$ \\
\hline Finanças e Fundos & $x$ & & $x$ & $x$ & $x$ & $x$ \\
\hline Serviços de Suporte & $x$ & & $x$ & $x$ & $x$ & \\
\hline Mercado & & & $x$ & $\mathrm{x}$ & & $\mathrm{x}$ \\
\hline Cultura & $x$ & & $x$ & $x$ & & $x$ \\
\hline Políticas Públicas & $x$ & $x$ & $x$ & & $x$ & $x$ \\
\hline
\end{tabular}

Fonte: autores

Para fins desta pesquisa, definem-se nove categorias para compor um ecossistema empreendedor. Elas são: investidores, capital humano, universidades, instituições de suporte, finanças e fundos, serviços de suporte, mercado, cultura e políticas públicas. A categoria "mentores" não faz parte do framework, pois só foi considerada por um dos autores dentre os analisados no Quadro 1.

Capital humano se refere ao conhecimento geral que os indivíduos obtiveram através de educação formal e experiências próprias (HAYTER, 2018), bem como mão de obra disponível, dado que a existência de um ecossistema empreendedor visa o progresso econômico através de novos empreendimentos (Isemberg, 2011).

A categoria investidores está relacionada com pessoas ou instituições com conhecimento ou interesse no meio empreendedor que, com capital privado, facilitam, configuram e subsidiam a geração de produtos tecnológicos ou culturais emergentes (Ngongoni, Grobbeller 2017).

No âmbito de finanças e fundos, acrescidos de investidores, encontram-se instituições privadas responsáveis pelo financiamento do empreendedorismo (Arrudaet al, 2014), fator considerado de suma importância no desenvolvimento de qualquer setor de crescimento disruptivo e/ou empreendedor (Nicotra et al, 2018).

As universidades e instituições de pesquisa, por sua vez, aumentam a capacidade intelectual da população e a propagação de conhecimento (Agarwal et al, 2004), e, pela sua própria natureza, podem ser associadas ao desenvolvimento de um ecossistema empreendedor (Nicotra et al, 2018).

As instituições de suporte estão relacionadas a organizações criadas para suportar o crescimento de empresas empreendedoras, como hubs, aceleradoras e incubadoras, através de recursos de suporte de negócios e serviços que podem incluir espaço físico, capital, mentoria, serviços e conexões (Nicotra et al., 2018).

Em políticas públicas, estão inseridas instituições governamentais que apoiam o empreendedorismo e são responsáveis por facilitar o desenvolvimento de empresas (Arruda et al., 2014; Novaes, Andrade, 2018).

O termo mercado se refere a rede de empreendedores e aos consumidores primários (Nicotra et al., 2018), estes prontos para consumir e absorver novos produtos e, posteriormente, disseminá-los, fortalecendo o empreendimento (Arruda et al., 2014). 
Os serviços de suporte se caracterizam pela presença de prestadores de serviços que trabalham diretamente com as necessidades das empresas empreendedoras já consolidadas e formam uma rede de apoio a novos empreendimentos, realizando atividades não essenciais de forma terceirizada (Carvalho, 2016).

Por fim, cultura abrange as características sociais da comunidade e as formas com que os atores e indivíduos se relacionam (Isemberg, 2011). Uma série de estudos revela como a cultura local molda a propensão de empreendedores em potencial a criar negócios e inovar (Chua et al., 2015).

Percebe-se, assim, que os distintos atores do ecossistema empreendedor mostram a não-linearidade e a complexidade do mesmo (Cavallo, 2018) e devem ser analisados de forma conjunta e inter-relacionada para a determinação de um ecossistema específico. Portanto, as combinações desses elementos serão únicas para cada região, mas faz-se necessário que todas as categorias sejam representadas de alguma forma (Isemberg, 2011; Nicotra, 2018).

\subsection{Planejamento dos casos}

\subsubsection{Definição das unidades de análise}

$\mathrm{Na}$ cidade de Lorena, as categorias e atores que as compõem são apresentados a seguir. Esta lista proveio de informações obtidas pelos autores e que são de conhecimento público, bem como de conversas informais com alguns atores já conhecidos deste ecossistema.

1. Investidores: Pessoas que investem ou estariam dispostas em investir em atividades empreendedoras na cidade de Lorena;

2. Capital Humano: Estudantes do tema e empreendedores em geral;

3. Universidades: as três universidades instaladas em Lorena: USP, Unisal e Unifatea;

4. Instituições de suporte: SEBRAE (Serviço Brasileiro de Apoio às Micro e Pequenas Empresas), ACIAL e Agência de Inovação da USP;

5. Finanças e Fundos: representantes de bancos de Lorena.

6. Serviços de suporte: advogados, contadores e agentes imobiliários que apoiam empreendedores e a atividade empreendedora;

7. Mercado: Consumidores de produtos de atividades empreendedoras residentes em Lorena;

8. Cultura: Indivíduos ou organizações que incentivam a disseminação e fortalecimento da cultura empreendedora na cidade;

9. Políticas Públicas: Secretarias da Prefeitura de Lorena.

\subsubsection{Planejamento da coleta de dados}

Definiu-se que a coleta de dados deveria ser feita por meio de entrevistas com três atores de cada uma das nove categorias, totalizando 27 entrevistas semiestruturadas. Esse tipo de entrevista foi escolhido devido à diversidade de atores e setores que serão abordados. A vantagem deste tipo de entrevistas é o aumento da abrangência dos dados, além disso lacunas lógicas podem ser antecipadas e evitadas e as entrevistas ocorrem com mais fluidez (Patton, 1980). Um roteiro de perguntas foi elaborado a partir da fundamentação teórica e foi aplicado em um teste piloto para sua validação e/ou aprimoramento. 


\subsection{Teste piloto}

O teste piloto foi realizado com três atores de categorias diferentes do framework. Ele foi feito por meio de entrevistas presenciais. As perguntas se mostraram claras e precisas, com exceção de uma delas, que foi aprimorada.

As entrevistas foram gravadas e, posteriormente, transcritas. Com a transcrição percebeu-se que, apesar das dificuldades de interpretação de uma das perguntas, os dados coletados foram satisfatórios e foi necessária, apenas, uma pequena alteração nesta questão. O questionário a ser usado na coleta de dados continha cinco perguntas sobre: conhecimento sobre ecossistema empreendedor; empreendedorismo e agentes empreendedores na cidade de Lorena, os beneficiados pela atividade empreendedora; a percepção sobre Lorena ser uma cidade empreendedora.

\subsection{Coleta de dados}

Nesta etapa, foram realizadas 27 entrevistas, três com cada uma das nove categorias definidas no framework de pesquisa. Os entrevistados apresentaram perfis diferentes de idade, gênero, formação e atuação.

O quadro 2 mostra a relação dos entrevistados por categoria e suas características sociais. A primeira coluna apresenta cada uma das nove categorias. A segunda coluna (Cód.) atribui um número sequencial a cada um dos vinte e sete entrevistados. As terceira e quarta colunas apresentam, a idade e o gênero do entrevistado, respectivamente. A quinta coluna mostra a formação acadêmica ou técnica do entrevistado, e a sexta e última coluna mostra a área de atuação dos entrevistados, de forma a definir o perfil de cada um deles.

Vinte e duas entrevistas foram realizadas presencialmente e cinco foram realizadas por meio de plataformas digitais. Todas as entrevistas foram transcritas e preparadas para a análise.

Quadro 2

Relação dos entrevistados por categoria

\begin{tabular}{|c|c|c|c|c|c|}
\hline Categoria & Cód. & Idade & Gênero & Formação & Atuação \\
\hline \multirow{3}{*}{ Investidores } & 1 & 38 & $\mathrm{~F}$ & Publicidade e Propaganda & Empresária e Fotógrafa \\
\hline & 2 & 50 & M & Engenharia de Telecomunicações & Coordenador de Vendas; Empresário \\
\hline & 3 & 59 & M & Técnico em Química & Empresário \\
\hline \multirow{3}{*}{$\begin{array}{c}\text { Finanças e } \\
\text { Fundos }\end{array}$} & 4 & 37 & $\mathrm{~F}$ & Licenciatura em Geografia & Gerente do Banco do Povo \\
\hline & 5 & 26 & $\mathrm{~F}$ & Administração & Gerente Administrativa do Sicredi \\
\hline & 6 & 30 & $\mathrm{~F}$ & Administração & Gerente de Conta no Sicredi; Empresária. \\
\hline \multirow{3}{*}{$\begin{array}{l}\text { Capital } \\
\text { Humano }\end{array}$} & 7 & 39 & $\mathrm{~F}$ & Secretariado Executivo & Empresária \\
\hline & 8 & 39 & $\mathrm{~F}$ & Terapia Ocupacional & Empresária \\
\hline & 9 & 37 & $\mathrm{~F}$ & Letras & Empresária \\
\hline \multirow{3}{*}{ Cultura } & 10 & 21 & M & Estudante de Engenharia & Entidade estudantil \\
\hline & 11 & 40 & $\mathrm{M}$ & Direito & Secretário de Cultura e Turismo \\
\hline & 12 & 59 & M & Jornalismo & Escritor, Diretor e Empresário \\
\hline \multirow{3}{*}{$\begin{array}{l}\text { Serviços de } \\
\text { Suporte }\end{array}$} & 13 & 37 & $\mathrm{~F}$ & Direito & Advogada e Empresária \\
\hline & 14 & 38 & $\mathrm{~F}$ & Direito & Advogada e ramo imobiliário \\
\hline & 15 & 26 & $\mathrm{M}$ & Direito & Advogado e Empresário \\
\hline \multirow{3}{*}{ Universidades } & 16 & 58 & M & Administração & Professor Universitário \\
\hline & 17 & 33 & M & Administração & Professor Universitário e Consultor Empresarial \\
\hline & 18 & 41 & M & Engenharia Industrial Química & Professor Universitário \\
\hline
\end{tabular}




\begin{tabular}{|c|c|c|c|c|c|}
\hline Categoria & Cód. & Idade & Gênero & Formação & Atuação \\
\hline \multirow{4}{*}{$\begin{array}{c}\text { Instituições de } \\
\text { Suporte }\end{array}$} & 19 & 56 & $\mathrm{M}$ & Engenharia de Produção Elétrica & Presidente da ACIAL \\
\cline { 2 - 6 } & 21 & 31 & $\mathrm{M}$ & $\begin{array}{c}\text { Mestrado em Biotecnologia, } \\
\text { Estudante de Engenharia }\end{array}$ & Estagiário e Microempreendedor \\
\cline { 2 - 6 } & 22 & 36 & $\mathrm{M}$ & Gestão e Logística; Mestre. & Secretário de Desenvolvimento Econômico \\
\hline \multirow{3}{*}{$\begin{array}{c}\text { Políticas } \\
\text { Públicas }\end{array}$} & 23 & 65 & $\mathrm{M}$ & Engenheiro Químico Industrial & Secretário do Meio Ambiente \\
\cline { 2 - 6 } & 24 & 42 & $\mathrm{M}$ & Direito & Assessor de Deputado Federal \\
\hline \multirow{3}{*}{\begin{tabular}{l} 
Mercado \\
\cline { 2 - 6 }
\end{tabular}} & 25 & 50 & $\mathrm{~F}$ & Técnico em Contabilidade & Assistente Técnico na USP \\
\cline { 2 - 6 } & 27 & 23 & $\mathrm{~F}$ & Estudante de Engenharia & Professor Universitário \\
\hline
\end{tabular}

Fonte: autores

\subsection{Análise de dados}

Os dados obtidos foram tratados conforme o método da Análise de Conteúdo e da Triangulação.

A Análise de Conteúdo é composta por cinco etapas: preparação da informação, que consiste na identificação das amostras; unitarização, definição do elemento único a ser submetido à classificação; categorização, agrupamento de dados contendo semelhanças; descrição, expressão dos significados das mensagens; e, por fim, interpretação do conteúdo (Moraes, 1999).

O conceito de triangulação provém da técnica de navegação, em que se tomam três pontos diferentes para se determinar uma localização (Easterby-Smitht al, 1999). Foi definida por Zappellini e Feuerschütte como:

Procedimento que combina diferentes métodos de coleta e de análise de dados, diferentes populações/sujeitos (ou amostras/objetos), diferentes perspectivas teóricas e diferentes momentos no tempo, com o propósito de consolidar suas conclusões a respeito do fenômeno que está sendo investigado (ZAPELLINI, FEUERSCHÜTTE, 2015, p. 246)

Foi utilizado o software francês Iramuteq (LINK-1) para a análise de conteúdo das entrevistas, de forma a facilitar o cruzamento de dados com a literatura, necessário para a conclusão da triangulação. O Iramuteq é um software gratuito e com fonte aberta, desenvolvido por Pierre Ratinaud (Lahlou, 2012; Ratinaud; Marchand, 2012), que permite fazer análises estatísticas sobre corpus textuais. As entrevistas foram transcritas e passaram por uma leitura minuciosa de forma a identificar possíveis erros que pudessem interferir nas análises feitas pelo software. Palavras-chaves e frases relevantes foram marcadas de maneira que os autores pudessem fazer um cruzamento entre a análise pessoal e subjetiva com as análises estatísticas do Iramuteq.

Para a análise no software, as entrevistas foram segmentadas por perguntas, ou seja, cada resposta da mesma pergunta dos 27 entrevistados compôs um corpus de texto ("um conjunto de textos") a serem analisados. Foram analisados cinco corpus constituídos por 27 textos, as respostas dadas para cada uma das cinco perguntas do roteiro usado com os entrevistados.

O software permite que cada texto do corpus possa ser identificado de acordo com o interesse do pesquisador, através de uma linha de comando. Na presente análise, os textos foram identificados de acordo com as categorias do framework as quais os atores pertenciam, idade e sexo. As categorias foram enumeradas de 1 a 9 conforme segue: 1. Investidores; 2. Finanças e Fundos; 3. Capital Humano; 4. Cultura; 5. Serviços de Suporte; 6. Universidades; 7. Instituições de Suporte; 8. Políticas Públicas e 9. Mercado. Para o gênero utilizou-se os códigos 1 e 2, masculino e feminino, respectivamente. Assim, o software foi programado para enunciar, por exemplo, a 
resposta de um ator de 65 anos da categoria políticas públicas a partir do seguinte comando: *****cat_8 *ida_65 *sex_1.

Dessa forma, foi possível analisar como cada tópico de pesquisa se relacionava de acordo com as características da segmentação de interesse. O software realiza cinco tipos de análise textual: Nuvem de palavras; análise de similitude; análises lexicográficas clássicas; especificidades e método da classificação hierárquica descendente. Na presente pesquisa foram utilizados os quatro primeiros tipos de análises.

A nuvem de palavras propõe um agrupamento de palavras de acordo com suas frequências de ocorrências. A análise de similitude, por sua vez, permite identificar as coocorrências, terminologia utilizada no software, entre as palavras e possibilita ver indicações de conexões entre elas. As análises lexicográficas clássicas identificam e reformatam o texto, reduz as palavras às suas raízes e identifica formas ativas e complementares. Por fim, a análise de especificidades permite que o texto seja analisado de acordo com as variáveis de caracterização do texto (Camargo Ejusto, 2013).

\subsubsection{Sobre ecossistema empreendedor}

A primeira pergunta (Você sabe o que é um ecossistema empreendedor?) teve como objetivo verificar com cada um dos entrevistados o seu nível de conhecimento sobre o conceito de ecossistema empreendedor.

No Iramuteq foram identificados 27 textos compondo o corpus e 649 ocorrências, indicando que as respostas dadas pelos entrevistados foram curtas, fato que condiz com o caráter da pergunta.

Ao se comparar os tipos de respostas em relação ao gênero do entrevistado, não foram identificadas quaisquer diferenças na frequência das formas e termos utilizados. No entanto, quando analisados por categoria, as respostas da categoria 6 (Universidades) foram mais consistentes em relação a todas as demais categorias. Ou seja, os atores das universidades ou tinham conhecimento do conceito ou se mostraram mais seguros em tentar aproximar uma resposta. Em contrapartida, as categorias que apresentaram menor conhecimento do conceito foram as 3 (Capital Humano) e 4 (Cultura). Esse fato, principalmente na categoria 3, sugere um possível despreparo dos empreendedores entrevistados no que diz respeito ao conhecimento deste conceito.

A partir das estatísticas textuais e especificidade pode-se perceber que a palavra mais comum nas respostas foi não, conforme mostra a Figura 1, que representa a nuvem de palavras gerada com esse corpus.

Figura 1

Nuvem de palavras da Pergunta 1

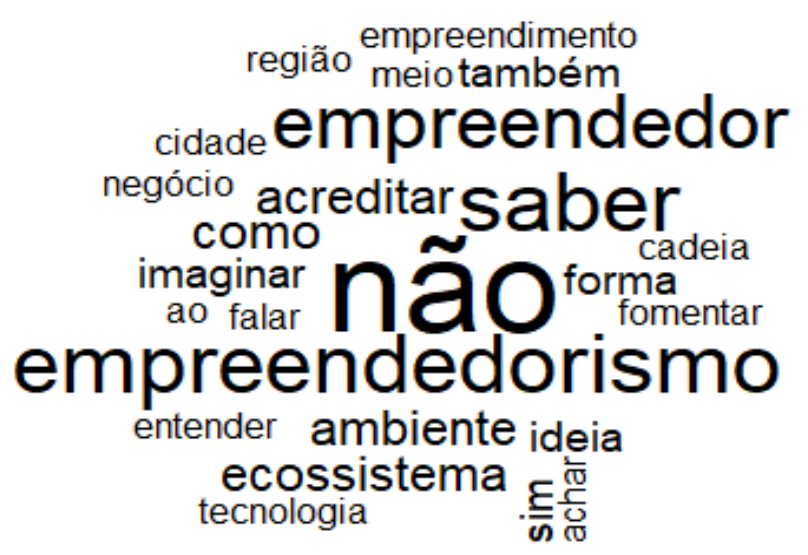

Fonte: extraído do software Iramuteq

No entanto, mesmo afirmando que não sabiam ou tentando aproximar as respostas, pode-se perceber que os entrevistados tinham uma noção sobre o assunto. As palavras negócio, fomentar, ambiente, cadeia e outras 
estão relacionadas com a definição real do que é um ecossistema empreendedor. Um exemplo disso pode ser observado na fala:

"Acredito que seja um ambiente propicio ao empreendedorismo onde existe uma interação e conexão entre diversas áreas e diversos empreendedores." (Entrevistada 13 - Categoria 5: Serviços de Suporte)

\subsubsection{Sobre Empreendedorismo Local Lorena, cidade empreendedora?}

A segunda pergunta (Você acredita que Lorena seja uma cidade empreendedora? Explique.) teve como objetivo verificar a percepção dos entrevistados sobre Lorena ser ou não uma cidade empreendedora.

Assim como na pergunta anterior, foram identificados 27 textos no corpus, dessa vez separados em 65 segmentos de texto. A palavra mais utilizada nas respostas dos entrevistados foi não, com 40 ocorrências. No entanto, isso não significa necessariamente que a maioria das pessoas entende que Lorena não é uma cidade empreendedora, mas aponta para a falta de um perfil e movimento empreendedor claro. A fala de um dos entrevistados reflete isso:

"Eu acredito que, de uma maneira geral, o Vale do Paraíba é empreendedor. [...] Não há um movimento organizado que dê grandes oportunidades e fomente isso. Eu acho que é sim um ambiente empreendedor, Lorena, mas muito individualista e não um ambiente que brota isso natural como uma cultura." (Entrevistado 17 - Categoria 6: Universidades)

Respostas similares a esta foram recorrentes, indicando que Lorena tem o potencial para se desenvolver e tornar-se, cada vez mais, empreendedora. A análise de similitude proposta pelo Iramuteq mostra que os entrevistados conseguiram identificar alguns fatores relevantes para o fomento do empreendedorismo no local, conforme pode ser visto na Figura 2. A partir dessa análise é possível identificar as principais ocorrências entre as palavras e as conexões entre elas, identificando, assim, a estrutura do conteúdo do corpus textual. As palavras mais evidentes na análise são "Não", "Muito", "Cidade", "Empreendedor", "Acreditar" e "Sim". Delas se ramificam palavras como "empresa", "universidade", "comércio", "potencial" e "desenvolvimento".

Assim, o discurso dos participantes apresenta relações plausíveis com a literatura para um ecossistema empreendedor. Ele mostra a relação que os atores fizeram entre a atividade empreendedora e as características da cidade, ressaltando as universidades, empresas e comércio. Além disso, associaram essas características ao potencial de desenvolvimento da cidade como um todo, de oportunidades para a população, investimento e crescimento econômico. Esses fatores são ratificados pela fundamentação teórica apresentada e se relaciona diretamente com o framework proposto pelos autores. 
Figura 2

Análise de similitude da Pergunta 2

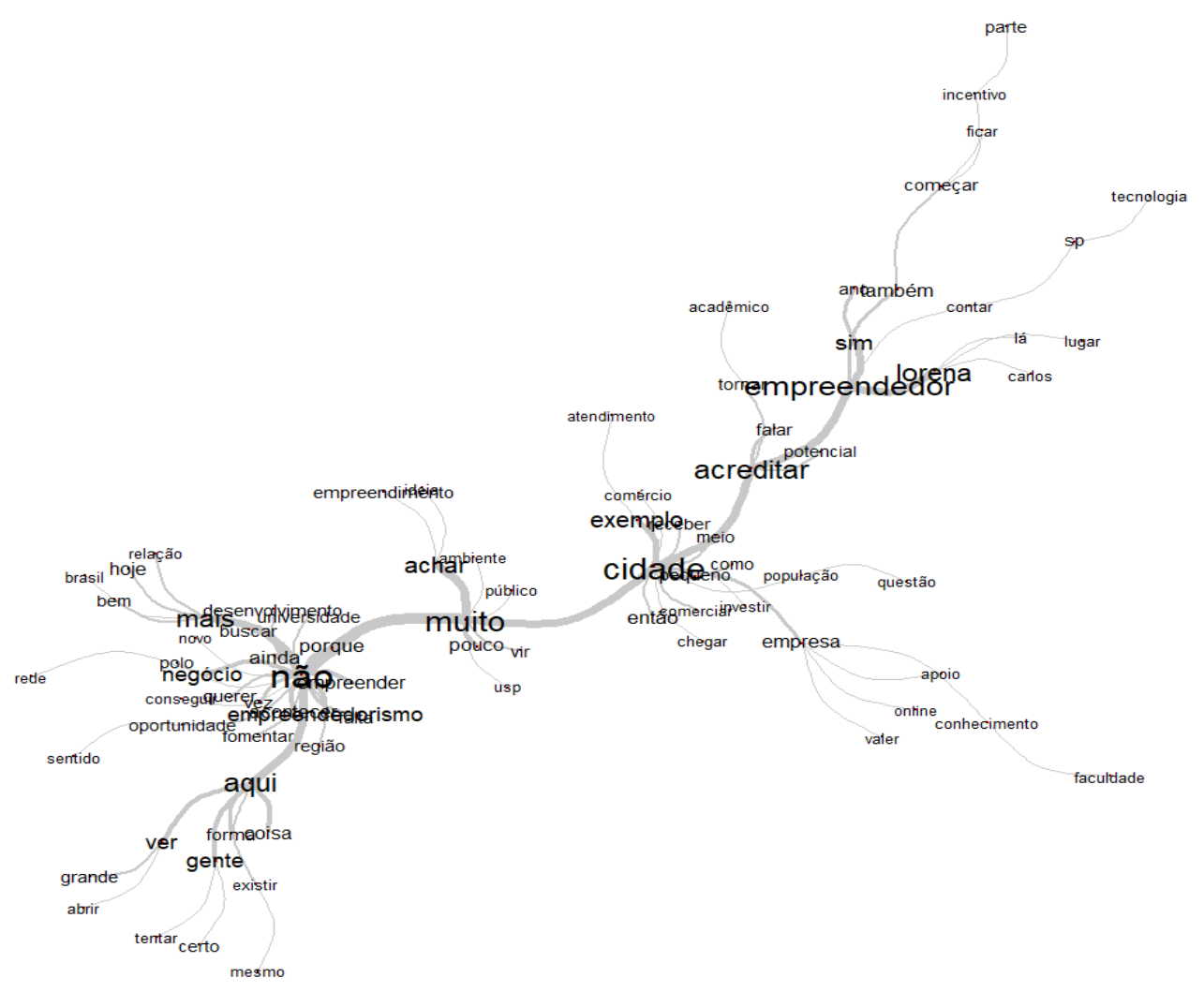

Fonte: extraído do software Iramuteq

\section{Agentes relevantes para o empreendedorismo local}

A terceira pergunta (Quem são as pessoas físicas ou jurídicas relevantes para a atividade empreendedora de Lorena? Explique e dê exemplos.) teve como objetivo verificar a percepção acerca das pessoas relevantes para a manutenção da atividade empreendedora em Lorena. Todos os entrevistados responderam à pergunta citando pessoas físicas e empresas que julgaram relevantes.

Após aplicar um filtro e retirar palavras que poluíam a percepção do resultado esperado, como conectivos, adjuntos e advérbios, obteve-se uma nuvem de palavras para análise. Na Figura 3 vê-se, claramente, os atores que se destacaram: Empreendedor, Universidade, Empresa, Prefeitura, Empresário, Professor, e SEBRAE foram citados e se conectam com o framework definido, o que indica que as pessoas têm uma percepção coerente dos atores relevantes para a manutenção do empreendedorismo da cidade. 
Figura 3

Nuvem de palavras após aplicação de filtro

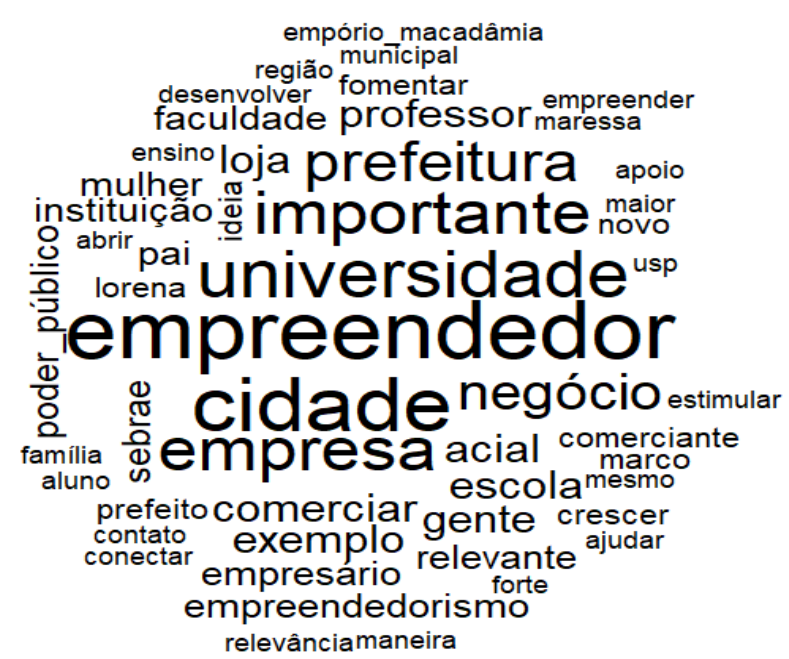

Fonte: extraído do software Iramuteq

$\mathrm{Na}$ análise de similitude feita para esse corpus textual, usando os mesmos filtros da nuvem de palavras da Figura 3, pode-se inferir essa percepção individual de cada entrevistado. Em pessoas físicas relevantes, que apareceram em pelo menos 5 respostas, identificou-se o prefeito municipal, um professor da USP e uma empresária local. Outras pessoas físicas não foram citadas mais de 5 vezes. Em pessoas jurídicas, observa-se Universidades, Prefeitura, ACIAL (Associação Comercial) e SEBRAE, por exemplo. Além disso, percebe-se também que o termo mulheres foi bastante citado, e, a maioria de empresários citados foram mulheres.

\section{Beneficiados pela atividade empreendedora}

A quarta pergunta (Quem é beneficiado pelas atividades empreendedoras de Lorena? Por quê?) teve como objetivo apurar os beneficiados pelas atividades empreendedoras na percepção dos entrevistados. A maioria dos entrevistados ressaltou que a população e sociedade, como um todo, ganham pela atividade empreendedora. A fala de um dos entrevistados reforça isso:

"Eu diria que nesse contexto, todos nós. A sociedade como um todo, todos nós aproveitamos dessa oportunidade. Obviamente que aquele que está diretamente envolvido tem benefício direto com o sucesso do seu empreendimento. Mas a comunidade como um todo ganha, sobretudo com bons projetos." (Entrevistado 11 - Categoria 4 - Cultura).

Nas análises do Iramuteq, a forma ativa (palavras dadas como relevantes para o contexto) mais utilizada foi população, seguida por cidade. Na análise de especificidade, as duas categorias que menos utilizaram a palavra população foram as Categorias 4 (Cultura) e 7 (Instituições de Suporte). No entanto, a fala do entrevistado 11 acima mostra que, apesar de não ter usado o termo comum população, essencialmente, a percepção do entrevistado foi a mesma.

A análise de similitude revela alguns pontos importantes. Pode-se perceber que, ao analisar as zonas coloridas da Figura 4, alguns grupamentos de palavras que tenderam a aparecer juntos. 
Figura 4

Análise de similitude para a Pergunta 4 com halo

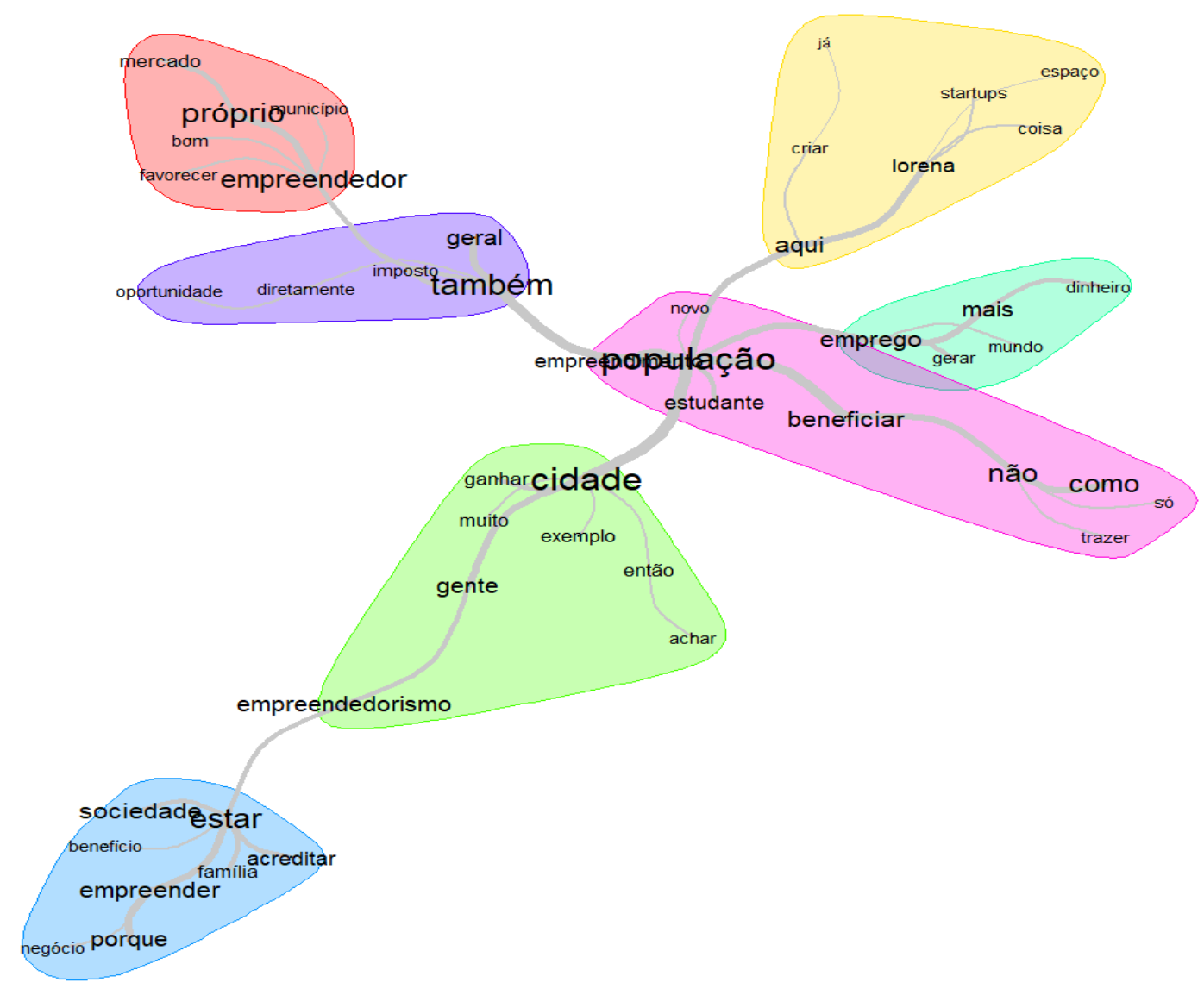

Fonte: extraído do software Iramuteq

Nessa análise percebe-se que o termo população se encontra no centro e todas as ramificações partem dele. Isso mostra que a população foi o tema central das construções que constituíam o corpus textual, indicando que, para os entrevistados, a população é beneficiada, de modo geral, pela atividade empreendedora.

\subsubsection{Lorena, um ecossistema empreendedor?}

Por fim, a quinta e última pergunta (Você acredita que Lorena seja um ecossistema empreendedor? Por quê?) teve como objetivo verificar, na percepção de cada um dos entrevistados, a existência ou não de um ecossistema empreendedor em Lorena. A maioria dos entrevistados afirmou que sim, existe um ecossistema empreendedor em Lorena. No entanto, apontaram fatores ausentes ou fracos que dificultam o desenvolvimento do ecossistema, conforme mostra a resposta de um dos entrevistados:

"Eu acredito que existe sim. O contexto hoje é que esse ecossistema não é visível. Não existe como formalidade o ecossistema criado. Por exemplo, não temos hoje serviços de apoio que esteja ligado diretamente a esse contexto. Você não consegue enxergar o ecossistema como uma rede formal, mas ele existe." (Entrevistado 22 - Categoria 8: Políticas Públicas).

Apesar de a maioria das respostas ter sido positiva para a existência de um ecossistema empreendedor na cidade de Lorena, a forma ativa mais utilizada foi não, com 41 ocorrências, e, em seguida, sim, com 17 ocorrências. Mas, novamente, isso não significa que, no contexto geral, os entrevistados acreditem que não exista o ecossistema empreendedor na cidade. A Figura 6 mostra que algumas construções indicam esse fenômeno: o ecossistema existe, mas não está estruturado. 
Figura 5

Análise de similitude da Pergunta 6

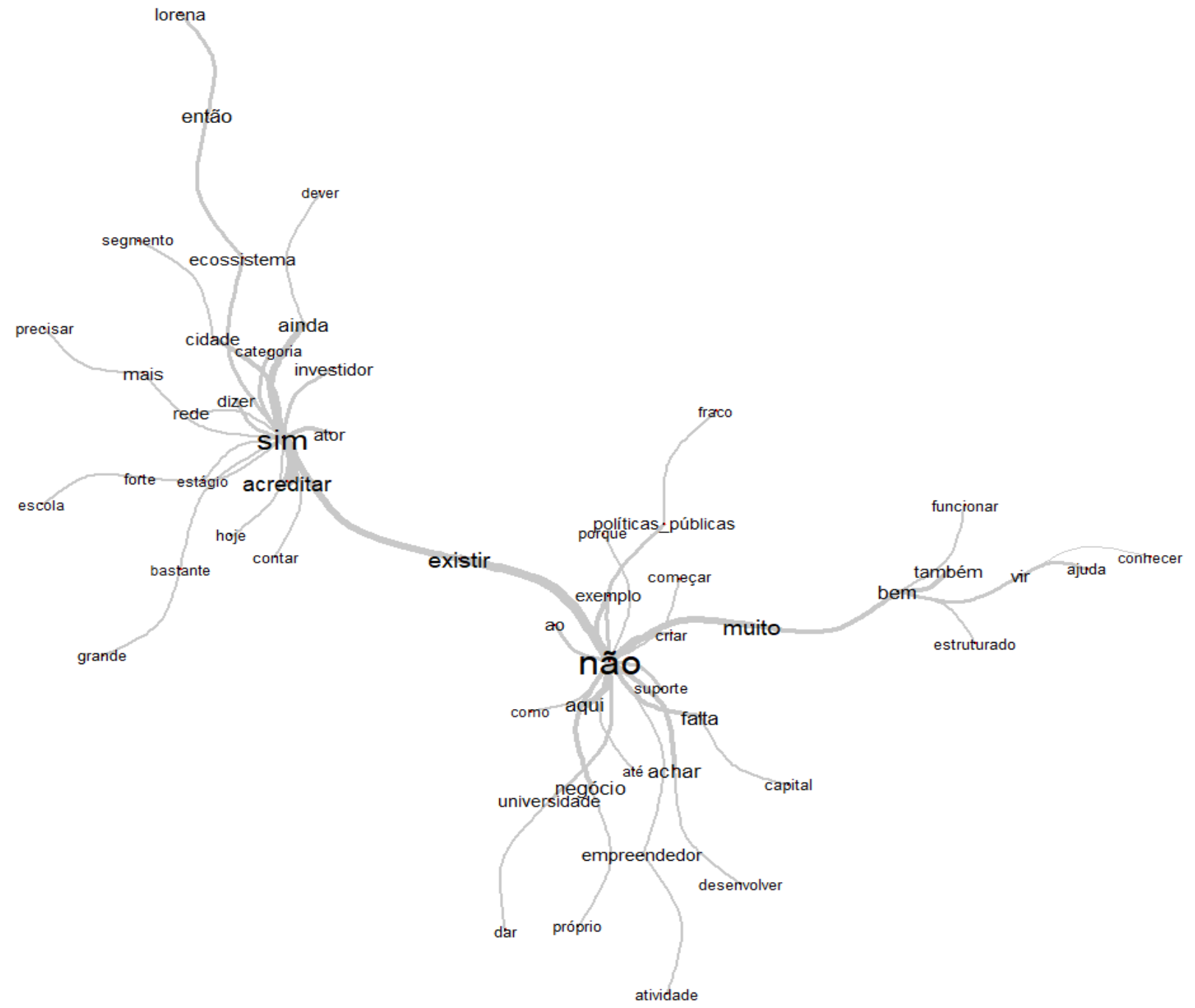

Fonte: extraída do software Iramuteq

Na Figura 6 é possível observar, também, categorias e atores que foram citados. No entanto, apenas com a análise de similitude, não se pode afirmar que termos como políticas públicas, universidade, investidor e escola foram considerados por contribuírem ativamente para com o ecossistema empreendedor, ou o contrário.

As análises feitas a partir do Iramuteq apontam que não é possível medir o grau de desenvolvimento desses fatores e, tampouco, do ecossistema empreendedor existente na cidade. A resposta de um dos entrevistados se destaca devido a observações pertinentes que foram feitas acerca do grau de maturidade que esse ecossistema se encontra:

"Eu daria uma nota de maturidade, de 1 a 5 eu daria uma nota 2 ou 2,5. Você tem uma universidade, mas falta cultura de empreendedorismo e a busca de capital. Temos uma série de indústrias ao redor, mas elas não se beneficiam do conhecimento da cidade. E empresas criadas nas universidades não contam com linhas de crédito acessíveis para começar o próprio negócio. Então falta o desenvolvimento de alguns fatores." (Entrevistado 2 - Categoria 1 - Investidores). 
Além disso, vê-se também que não há a formalização dessa rede de atores que sustentam o empreendedorismo em Lorena. Ou seja, não há interação entre os atores, o que dificulta o desenvolvimento do ecossistema empreendedor.

\subsection{0 ecossistema empreendedor de Lorena}

O objetivo geral deste trabalho foi analisar o potencial de desenvolvimento do ecossistema empreendedor da cidade de Lorena visando seu fortalecimento e sinergia. No que diz respeito a existência de um ecossistema empreendedor, os dados apurados a partir das entrevistas realizadas, bem como a posterior análise, apontam para a existência de um ecossistema em Lorena, mas em um estágio inicial.

Corallo, Errico e Latino (2018) propõem três níveis de desenvolvimento para um ecossistema de negócios: Nível 1 - as ideias estão em fase de pré-incubação, é suportada financeiramente e está em uma fase competitiva; Nível 2 - é a fase de criação de startups nos níveis industriais, universitários e acadêmicos; e Nível 3 - há alto incentivo de incentivo público e privado que influenciam o crescimento econômico. Esse modelo relaciona-se com ambientes tecnológicos, mas ao ser aplicado nesse estudo, aponta que o ecossistema empreendedor de Lorena encontra-se em uma fase embrionária e informal a caminho do Nível 1.

Jucevicius et al. (2016), por sua vez, sugerem que ecossistemas empreendedores emergentes, por terem recursos limitados de investimento em diversos segmentos, não tem um framework sólido e estruturado, e isso faz com que muitos micro níveis da atividade empreendedora devam ser analisados individualmente para medir o grau de desenvolvimento desse sistema. Esses micro níveis, nessa pesquisa, são dados como as nove categorias que compõem um ecossistema empreendedor.

Assim, analisando as categorias que compõem um ecossistema empreendedor (o framework de pesquisa), percebe-se que existem diferenças entre elas, ou seja, no ecossistema empreendedor de Lorena, existem categorias bem desenvolvidas e outras não tão bem desenvolvidas. Um exemplo é a Categoria 1 (Investidores), que não foi citada como presente ou como de conhecimento dos demais atores das outras categorias. Não há, por exemplo, um grupo de investidores-anjo ou alguma forma de investimento em capital de risco na cidade. Isso se relaciona também à Categoria 2 (Finanças e Fundos) que fica restrita aos bancos tradicionais e cooperativas de crédito. Essas instituições podem apresentar condições favoráveis ao desenvolvimento de novos negócios, mas isso não é de conhecimento do público. No entanto, esse resultado deve ser analisado com ponderação, uma vez que o estudo se limitou exclusivamente à cidade de Lorena. Essas duas categorias não necessariamente precisam estar estabelecidas na cidade para investir na atividade empreendedora local.

A Categoria 6 (Universidades) é uma das mais desenvolvidas, junto com a Categoria 3 (Capital Humano). A atividade acadêmica na cidade é muito fomentada, e isso contribui para o desenvolvimento de capacitação de recursos humanos. Entretanto, os resultados sugerem que o conhecimento gerado fica restrito as Universidades, não beneficiando de uma forma direta a população do ecossistema empreendedor. As Categorias 5 (Serviços de Suporte) e 7 (Instituições de Suporte) foram retratadas como secundárias, mas importantes. Estão presentes na cidade, mas não foi possível constatar que atuam como incentivadoras do empreendedorismo. A Categoria 9 (Mercado) foi a que menos percebeu-se relevante para a manutenção do empreendedorismo na cidade, apesar de ser fundamental para o seu fomento, dado que são os potenciais consumidores para os produtos da atividade empreendedora em Lorena, mas nenhum dos entrevistados comentou sobre hábitos de consumo local.

Por fim, a partir das entrevistas realizadas, foi possível constatar que existe atividade empreendedora relacionada a serviços e comércio, mas não foi possível verificar existência de atividade empreendedora no ramo industrial. Mas isso não quer dizer que não exista e sim que, a partir dos 27 entrevistados, não foi possível identificá-la. As atividades acadêmicas tangenciam o empreendedorismo na cidade, mas poucos atores de fato cruzam a barreira universidade-sociedade, o que impede que boas ideias se desenvolvam na cidade. Percebe-se, 
então que falta uma ação mais ativa da Categoria 8 (Políticas Públicas) que fomente e valorize a atividade empreendedora na cidade. Fomento este que pode vir a tornar a atividade empreendedora mais comum e orgânica, o que, por consequência, pode vir a gerar uma cultura empreendedora.

Dessa forma, define-se o ecossistema empreendedor de Lorena como em fase inicial, com duas categorias (Universidades e Capital Humano) que se destacam em relação às demais e duas outras categorias (Investidores e Finanças e Fundos) que parecem ser o elo mais fraco do ecossistema. Além disso, as Políticas Públicas mostramse presentes na realidade empreendedora de Lorena, mas é necessário fortalecê-las, pois, assim, elas serão de conhecimento de todos e poderão alimentar o crescimento da Cultura empreendedora e movimentar o Mercado, trazendo possíveis consumidores para os produtos da atividade empreendedora. Em suma, o que foi constatado é que existem atividades sendo desenvolvidas e atores de uma certa relevância atuando no ecossistema empreendedor em Lorena, mas não de uma forma organizada e sincronizada.

\section{Considerações Finais}

\subsection{Dos objetivos da pesquisa}

A pesquisa teve como principal objetivo analisar o potencial de desenvolvimento do ecossistema empreendedor em Lorena. Assim, a partir da análise das 27 entrevistas realizadas, foi possível constatar a existência de um ecossistema empreendedor, contudo, em fase inicial e informal.

Foram identificadas algumas categorias de atores fundamentais para a manutenção desse ecossistema. Políticas públicas, universidades, instituições de suporte e capital humano mostraram-se muito relevantes, mas ainda carentes de incentivo e crescimento. Percebeu-se que a atividade empreendedora de Lorena tem uma participação muito ativa de mulheres, que, muitas vezes, estão à frente de empreendimentos inovadores e de sucesso na cidade.

As universidades, que são um dos pontos fortes de Lorena, necessitam maior interação entre elas, bem como com a cidade, de forma a agregar conhecimento e expandir o capital humano. Verificou-se também, que o elo mais fraco desse ecossistema, no que tange ao município de Lorena, se encontra no âmbito financeiro: Investidores e Finanças e Fundos. Não há instituições ou pessoas que cumprem com esse papel de forma visível e satisfatória na cidade.

Finalmente, contemplando o objetivo da pesquisa, as nove categorias foram identificadas na cidade e o grau de relacionamento entre seus atores revelou-se baixo. O ecossistema existe, mas em estágio inicial e necessita de incentivo do poder público, do setor financeiro e de grandes empresas, como também das universidades e da sociedade em geral, para criar sinergia e fortalecer a atividade empreendedora. Dessa forma, o ecossistema empreendedor de Lorena poderá se tornar forte e consolidado, pois tem potencial para isso.

\section{Referências bibliográficas}

AGARWAL, R. et al. (2004). Knowledge transfer through inheritance: Spin-out generation, development, and survival. Academy of Management Journal, 47(4), 501-522. https://doi.org/10.5465/20159599

ANDRADE, H. S.; SOTO URBINA, L. M.; FOLLADOR, A. O. N. (2016A). Processos para a proteção da propriedade intelectual em Núcleo de Inovação Tecnológica. ESPACIOS (CARACAS), v. 37, p. 23.

ANDRADE, H. S.; SOTO URBINA, L. M.; FOLLADOR, A. O. N.; FOLLADOR, R. C. (2016B). Processes Proposal for the Intellectual Property Protection Management in a Technology Licensing Office from a Brazilian Scientific and Technological Institution. In: Portland International Conference on Management of Engineering and 
Technology (PICMET), 2016, Honolulu. Proceedings of PICMET '16: Technology Management for Social Innovation, 2016. p. 1672-1680.

BARDIN, L. (2006) Análise de conteúdo. Lisboa: Edições 70

BARROS, M. D et al. (2017). Análise multicritério em dados sobre empreendedorismo: um estudo bibliométrico. Revista Produção Online, [S.L.], v. 17, n. 3, p. 1069. Associação Brasileira de Engenharia de Produção ABEPRO. http://dx.doi.org/10.14488/1676-1901.v17i3.2764.

CAMARGO, B. V.; JUSTO, A. M. (2013). Tutorial para uso do software de análise textual IRAMUTEQ. Laboratório de Psicologia Social da Comunicação e Cognição - LACCOS Universidade Federal de Santa Catarina, Brasil.

CARVALHO, L. C.(2016). COMPREENDER O QUE SE ENTENDE POR ECOSSISTEMA EMPREENDEDOR: LISBOA COMO UMA CIDADE START UP. R-lego: Revista Lusófona de Economia e Gestão das Organizações, Lisboa, p.17-31.

CAVALLO, A.; GHEZZI, A.; BALOCCO, R. (2018). Entrepreneurial ecosystem research: present debates and future directions. International Entrepreneurship and Management Journal, [s.l.]. Springer Science and Business Media LLC. http://dx.doi.org/10.1007/s11365-018-0526-3.

CHUA, R. Y.; ROTH, Y.; LEMOINE, J. F. (2015). The impact of culture on creativity: How cultural tightness and cultural distance affect global innovation crowdsourcing work. Administrative Science Quarterly, 60, 189227. http://dx.doi.org/10.1177/0001839214563595

CORALLO, Angelo et al. (2018). A Framework Proposed in Order to Assuring the Entrepreneurial Ecosystem Sustainability through a Dynamic Model of Governance. 7th International Conference on Industrial Technology and Management, Lecce, p.421-426.

DAVIDSSON, P. (2003). the domain of entrepreneurship research: some suggestions. In J. Katz \& D. Shepherd (Eds.), v. 6 of Advances in entrepreneurship, firm emergence, and growth. p. 315-372.

EASTERBY-SMITH, M.; THORPE, R.; LOWE, A.(1999). Pesquisa gerencial em administração: um guia para monografias, dissertações, pesquisas internas e trabalhos de consultoria. São Paulo: Pioneira.

HAYTER, Christopher S. et al. (2018). Conceptualizing academic entrepreneurship ecosystems: a review, analysis and extension of the literature. The Journal of Technology Transfer, [s.l.], v. 43, n. 4, p.1039-1082. Springer Nature. http://dx.doi.org/10.1007/s10961-018-9657-5.

IBGE - Instituto Brasileiro de Geografia e Estatística (2019)

ISENBERG, D (2011). Babson Entrepreneurship Ecosystem Project. Babson College (BEEP).

JUCEVICIUS, Giedrius et al. (2016). The Emerging Innovation Ecosystems and "Valley of Death": Towards the Combination of Entrepreneurial and Institutional Approaches. Inzinerine Ekonomika-engineering Economics. v. 4, n. 27, p.430-438. https://doi.org/10.5755/j01.ee.27.4.14403

LAHLOU, S. (2012).Text Mining Methods: An answer to Chartier and Meunier. Papers on Social Representations, v.20, n.38, p.1-7.

LINK - 1: Iramuteq (2008). Disponível em: < www.iramuteq.org/>

LUIZ, O. R. (2017) Práticas baseadas na gestão de projetos por corrente crítica e o desempenho de portfólio de produtos: um survey em empresas brasileiras. 107 p. Dissertação (Mestrado em Engenharia de Produção) Faculdade de Engenharia de Bauru, Universidade Estadual Paulista, Bauru. 
MARCHAND, P.; P. RATINAUD. (2012). L'analyse de similitude appliqueé aux corpus textueles: les primaires socialistes pour l'election présidentielle française. Journées internationales d'Analyse statistique des Données Textuelles. JADT 2012, p.687-699.

MASON, C.; BROWN, R. (2014). Entrepreneurial Ecosystems and Growth Oriented Entrepreneurship. The Hague: OECD Leed Programme and the Dutch Ministry of Economic Affairs.

MEREDITH, J. (1998). Building operations management theory through case and field research", Journal of Operations Management, Vol. 16, pp. 441-54.

MIGUEL, P. A. C.(2007). Estudo de caso na engenharia de produção: estruturação e recomendações para sua condução. Produção, v. 17, n. 1. http://dx.doi.org/10.1590/ S0103-65132007000100015

MOORE, J. F. (1993). Predators and prey: a new ecology of competition. Harvard Business Review, v. 71, n. 3, 75-83.

MORAES, R. (1999). Análise de conteúdo. Revista Educação, Porto Alegre, v. 22, n. 37, p. 7-32.

NEUMEYER, X.; HE, S.; SANTOS, S. C. (2017). The Social Organization of Entrepreneurial Ecosystems. IEEE Technology and Engineering Management Conference (temscon), [s.I.].

NEUMEYER, X.; SANTOS, S. C.(2017). Sustainable business models, venture typologies, and entrepreneurial ecosystems: A social network perspective. Journal of Cleaner Production. USA, p. 4567-4579. http://dx.doi.org/10.1016/j.jclepro.2017.08.216

NEUMEYER, X.; SANTOS, S. C.; MORRIS, M. H. (2018). Who is left out: exploring social boundaries in entrepreneurial ecosystems? The Journal of Technology Transfer, [s.I.], v. 44, n. 2, p.462-484. Springer Science and Business Media LLC. http://dx.doi.org/10.1007/s10961-018-9694-0.

NGONGONI, C. N.; GROBBELAAR, S. S. (saartjie). (2017). Value Co-Creation in Entrepreneurial Ecosystems: Learnings from a Norwegian perspective. IEEEafricon2017proceedings, Stellenbosch, p.707-713.

NGONGONI, C. N.; GROBBELAAR, S.; SCHUTTE, C. (2017). The role of open innovation intermediaries in entrepreneurial ecosystems design. South African Journal of Industrial Engineering, [s.I.], v. 28, n. 3, p.5665, Stellenbosch University. http://dx.doi.org/10.7166/28-3-1839.

NICOTRA, Melita et al. (2017). The causal relation between entrepreneurial ecosystem and productive entrepreneurship: a measurement framework. The Journal of Technology Transfer, [s.I.], v. 43, n. 3, p.640673. Springer Nature. http://dx.doi.org/10.1007/s10961-017-9628-2.

Novaes, F. A. M. \& Andrade, H. S. (2018). Um ensaio sobre o direcionamento para a criação de projetos relacionados à políticas públicas. Espacios (Caracas), v. 39, n. 11, p. 1-12.

PATTON, M. Q. (1980). Qualitative Evaluation Methods, Sage Publications Inc., reprinted by permission of Sage Publications Inc.

SAUNDERS, M.; LEWIS, P.; THORNHILL, A. (2009) Research methods for business students. 5. ed. Harlow: Pearson Education Limited, $614 \mathrm{p}$.

STAM, F. C., \& SPIGEL, B. (2016). Entrepreneurial ecosystems. USE Discussion paper series, v. 16, n. 13.

URBAN, B. (2012). The venture creation process, entrepreneurial self-efficacy and competitiveness: a focus on technology enterprises. Journal of Strategic Innovation and Sustainability, v. 7, n. 3, p. 66-83. 
VOGEL, P. (2014). Building and assessing entrepreneurship ecosystems (Working Paper). Entrepreneurial Ecosystems and Growth-Oriented Entrepreneurship.

YIN, R. K. (2014). Estudo de Caso - Planejamento e Método. 5. ed. São Paulo: Bookman.

ZAPPELLINI, M. B.; FEUERSCHÜTTE, S. G. (2015). O Uso da Triangulação na Pesquisa Científica Brasileira em Administração. Administração: Ensino e Pesquisa, Rio de Janeiro, v. 16, n. 2, p.241-273.

http://dx.doi.org/10.13058/raep.2015.v16n2.238

\section{Esta obra está bajo una Licencia Creative Commons Attribución-NoCommercial 4.0 International \\ (cc) BY-NC}

